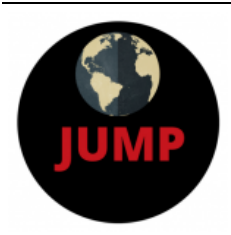

ISSN: 2574-3465 Print/ ISSN: 2574-3481 Online

Volume 3, Issue 1 (2019), pp. 23-32

(C) Journal of Underrepresented and Minority Progress

http://ojed.org/jump

doi: 10.32674/jump.v3i1.1016

\title{
Strategies for Recruiting Non-Hispanic Black Men into the Field of Pediatrics
}

\author{
Clark Gilford \\ Lisa Gwynn \\ Sarah Messiah \\ University of Miami, USA
}

\begin{abstract}
The focus of this work is on the root causes of the current lack of African American/non-Hispanic Black (NHB) men in the field of medicine and, especially, in pediatric medicine. The lack of diversity could serve to the detriment of the future directions of pediatric medicine. With supporting data, we argue that the low statistics of NHB men in the field reflect a social issue that can be resolved by the action of pediatricians across America. Therefore, we are convinced that the included information and suggested strategies are a valuable contribution to all scientific communities. Success of NHB male inclusion in medicine ultimately benefits the health of the public by facilitating cultural competence and increasing racial and ethnic concordance.
\end{abstract}

Keywords: American Association of Pediatrics, historically black colleges and universities, non-Hispanic Black, STEM, YMCA

The American Academy of Pediatrics (AAP) has long advocated for more opportunities for parents and children to experience seeing a racially, ethnically, and/or culturally concordant family pediatrician, supporting culturally competent care in the profession of pediatrics (Committee on Pediatric Workforce, 2013). Yet while the United States has made many great advances in medicine, advances in overcoming racial disparities have proven more challenging, especially in the field of pediatric medicine. The field of pediatrics alone is represented by a total of $5.49 \%$ of African American/non-Hispanic Black (NHB) pediatricians, of which a mere $1.47 \%$ 
are NHB males (see Table 1) for a total of about 1,300 men (Association of American Medical Colleges [AAMC], 2013). Diversity will generally be more valuable as the majority-minority shift warps America's demographics (e.g., the $24 \%$ of Hispanics under 18 in 2012 will increase to $38 \%$ in 2060 , while the $53 \%$ of Whites under 18 in 2012 will decrease to $33 \%$ by 2060) and knowledge on other ethnicities becomes ever-more essential (AAMC, 2015). Therefore, the belief emerging is that diversifying health and the pool of medical professionals will help to close disparity gaps and address shortages in terms of the number of practicing physicians in diverse geographic areas (Saha, Guiton, Wimmers, \& Wilkerson, 2008).

However, a major issue is that African American/NHB men are among some of the least represented groups in medical and pediatric practices. The American Association of Medical Doctors reports that only $4 \%$ of all U.S. medical doctors are NHB, and less than half $(45.8 \%)$ are men, resulting in less than $2 \%$ representation in total (AAMC, 2016). This is already an uphill battle due to the fact that Black or African Americans have the lowest rate of acceptance (34\%) to medical school compared with the other rates $(42 \%-44 \%)$ for Hispanic/Latino, Asian, and White matriculants (AAMC, 2016). It is hard to imagine how fewer than 2,000 NHB men (AAMC, 2013) will have appropriate representation among millions nationwide, especially as the nation's children will be constituted of $44.5 \%$ ethnic minority by 2020 (Committee on Pediatric Workforce, 2013). There are transparent benefits to having more NHB men in pediatrics and medicine. These benefits will be discussed, followed by an explanation of why it is still a problem to incorporate NHB males in pediatrics. Finally, three proposed strategies to solve the problem serve as a call to action for pediatricians across America.

Table 1. Numbers of pediatricians by race/ethnicity and gender in 2013. From "Demographics of Women Physicians and Pediatricians" by American Academy of Pediatrics, n.d. (https://www.aap.org/en-us/Documents/dwmep_women_med_ demographics.pdf). Copyright 2014 by the American Medical Association.

\begin{tabular}{lccccccc}
\hline & & & & & \multicolumn{3}{c}{$\begin{array}{c}\text { American } \\
\text { Indian/ }\end{array}$} \\
& White & Black & Hispanic & Asian & Other & Alaskan & Total \\
\hline All & 47,040 & 4,776 & 6,188 & 13,875 & 1,531 & 207 & 87,111 \\
Male & 20,356 & 1,277 & 2,557 & 5,170 & 713 & 67 & 36,639 \\
Female & 26,684 & 3,499 & 3,631 & 8,705 & 818 & 140 & 50,472 \\
\hline
\end{tabular}




\section{THE BENEFITS: WHY NHB MALES ARE NEEDED}

A general benefit to having NHB men active in pediatric medicine includes increasing cultural competency. Dr. Paul B. Rothman, Dean of the Medical Faculty and CEO of Johns Hopkins Medicine, understands this (Rothman, 2016). He asserted that patients have higher satisfaction with racial and lingual concordant physicians and visits last about 2 min longer, which is why he has advocated a fund to retain minority faculty and expand the science, technology, engineering, and mathematics (STEM) programs to more youth from low socioeconomic backgrounds (Rothman, 2016). Also, a study examining over 100 schools in a 2-year period shows that White students in diverse medical schools report being statistically more culturally competent than White students who attended more homogenous schools (Saha et al., 2008). This suggests positive impacts of diversity in medical school because it not only increases representation but also enables nonminority students to be more prepared to work with populations that are experiencing some of the worst disparities in the nation. Given that Whites currently remain at the majority of medical school matriculants $(51.2 \%)$ and medical school faculty (63\%; AAMC, 2016), it is important to expose these members of society to as much opportunity as possible for growth in cultural competence.

The most direct incentive for NHB men to be in pediatrics, however, is the fact that they will practice medicine in geographic areas where disparities are most prominent. A study from the AAMC revealed that minority graduates across the US are about twice as likely as nonminorities, $11.6 \%$ versus $6.1 \%$, to practice in federally designated manpower shortage areas (Symposium, 2001). This trend has continued into the modern day era. In 2015, as many as $51 \%$ of Black or African American medical students planned to practice in underserved communities, compared to $23 \%$ of Whites and Asians (AAMC, 2016). Numbers for desirability to practice in underserved communities have remained relatively consistent from 2005 to 2015, apart from Hispanics who showed a steady $6 \%$ increase from $33 \%$ in 2005 to $39 \%$ in 2015 (AAMC, 2016). What exactly are some disparities that exist in these underserved communities that NHB male pediatricians can address?

Some examples of the worst disparities in America are infant mortality and life expectancy from birth. Although infant mortality has been improved through programs like Women, Infants, \& Children Nutrition Program (WIC), mortality of Black babies is the worst (Noguera, 2003) and can still be twice as high as White babies (Khanani et al., 2010). As for life 
expectancy from birth, differences between White and Black people have historically remained large (Williams \& Sternthal, 2010). Black men lived 7.4 years shorter than White men in 1950 , but have only improved to a 6year difference by 2006 (Williams \& Sternthal, 2010). It is imperative that these outcomes are attended to from birth. So, if more minority doctors than non-minority doctors tend to aid children and families who tend to be minority and face disparities, one clear solution to America's issues would be to recruit and supply more NHB pediatricians.

While medical schools have shown marginal improvement in diversity in recent decades, the significance of fully inclusive minority representation is still difficult to capture at present. For example, the number of medical graduates from underrepresented communities generally increased from 9\% in 2003 to $15 \%$ in 2009 (Committee on Pediatric Workforce, 2013). However, while 1,410 Black men applied to medical school in 1978, only 1,337 applied in 2014 (Gallegos, 2016). This trajectory has shown minimal change over time and, perhaps, a degradation of the number of NHB male applicants over 30 years even though there are more seats to fill than ever before (Gallegos, 2016).

\section{THE PROBLEM: WHY ARE NHB MALES RELUCTANT TO ENTER INTO MEDICINE AND PEDIATRICS?}

From elementary to college, NHB males discern that they are unwelcome in a society that mitigates the intellectual accomplishments of men of color, making their opportunities more challenging. The struggles of discrimination have a negative effect on esteem and academic performance for Black boys (Noguera, 2003), which is supported by medical school application rates. In 2002, 18.2\% of Black high school sophomores aspired to be a doctor, but only $6.7 \%$ of applicants identified as Black/African American by 2012 (Morrison \& Cort, 2014). This is in direct contrast to the $48.1 \%$ of White sophomores and $5.8 \%$ of Asian sophomores who experienced upward trends of $60.2 \%$ and $23 \%$ as applicants (Morrison \& Cort, 2014). Results like these do not help combat the stigma NHB men face.

Stereotypes of lower expectations for Black men contaminate youth, especially entering teen years (Rao \& Flores, 2007), during which race becomes a more rigid aspect of their identity (Noguera, 2003). For example, the false perception that there are more Black men in prison than in college is automatically perceived as a barrier for pursuing a career as a physician (Rao \& Flores, 2007). Perhaps it started with other things like a teacher 
treating them differently, which plants the root of distrust between the student and teacher (Noguera, 2003). Maybe it was when peers excluded them for no apparent reason, or perhaps a stranger called them the "N" word. Internalizing subconscious negative stereotypes, such as "blackness being equal to ignorance," are detrimental to NHB men in their pursuit for higher education and advanced careers (Ben-Zeev, Dennehy, Goodrich, Kolarik, \& Geisler, 2014).

NHB male pediatricians would be effective in recognizing where children, particularly NHB boys, face heightened anxiety and confidence issues versus their peers. NHB boys are at the highest risk than any other cohort to be exposed to adverse stressors like inadequate nutrition, poverty, substance abuse, and high-crime neighborhoods (AAMC, 2015; Noguera, 2003). Correspondingly, since African American medical school applicants are more likely to report lower socioeconomic status (AAMC, 2015) and are more likely to practice in underserved communities (AAMC, 2016), NHB physicians likely seek home communities where they make the most impact and are familiar with hardships of NHB youth in the community. The lack of Black male physicians translates to the lack of role models to motivate NHB men to pursue the field of medicine, which has always caused a major predicament (AAMC, 2015). What strategies can be implemented in order to make a change and increase the number of NHB men in pediatrics?

\section{THREE STRATEGIES: COMMUNITY, EDUCATION, AND CULTURE}

\section{Strategy 1}

A first step would be to have pediatricians embrace community involvement. The right way to do this is the hard way, which is to engage with NHB boys and men outside of the office. Many NHB youth lack the resources or knowledge to pursue opportunities such as medicine (Noguera, 2003; Thomas, Manusov, Wang, \& Livingston, 2011), so it will be up to public health professionals to be creative and practical in community outreach (AAMC, 2015).

Pediatricians and medical scientists should continue to do important, extensive research in underserved areas and diverse settings such as preschools, schools, and after-school sites such as park and recreation centers. For instance, a pediatrician can sponsor a local junior high soccer team or contribute to college scholarships. Research at a local institution or community service at a local church are other examples of outreach for pediatricians to follow, as modeled by doctors at institutions like historically 
black colleges and universities like Morehouse College and Howard University, because health is much more than what is seen at hospitals (AAMC, 2015). The doctor's office is not always the answer, and as such pediatricians will need to "take it to the streets" so to speak, and to get buy in, and ultimately earn trust from the communities they serve.

\section{Strategy 2}

A second strategy includes pediatricians becoming integrated in secondary education. Institutions that are successful at getting NHB children to higher achievement levels employ strategies such as higher expectations, an orderly learning environment, and strong relationships with parents (Noguera, 2003). Coincidently, success in medical school matriculation is most often attributed to magnet programs, advanced courses, and supportive teachers (Thomas et al., 2011). NHB males are often discouraged from topics like math and history because of society's pressure for them to be involved in sports (Noguera, 2003), and one of the leading complaints among academic medicine is improved advising for high school and college for NHB males (AAMC, 2015).

As a consequence, pediatricians should reach out to schools and act as networks and mentors for adolescents (AAMC, 2015), assisting them along path toward a medical career and minimize the stress involved in the prerequisite and application process. As an NHB male, Clark was referred by his high school chemistry teacher to a local NHB male pediatrician. Clark was moved to believe that he could also contribute to society and impact medicine after his shadowing experience. Another example of action for pediatricians is to work in collaboration with an academic institution for allowing NHB males to get a glimpse of the medical education experience, such as Young Doctors DC (AAMC, 2015) or Oklahoma University Mini Medical School (Oklahoma Center for Neuroscience, 2010). The word-ofmouth of a teacher, parent, or neighborhood stakeholder is valuable, and NHB youth need explicit guidance to seek more opportunities within academics.

\section{Strategy 3}

A third and most essential strategy is for pediatricians to challenge the stereotype that frames NHB men as incapable of caring for children. As previously stated, NHB boys are predisposed to being highly influenced by unfavorable stereotypes from culture and media (Ben-Zeev et al., 2014; Rao \& Flores, 2007). A major misrepresentation that plays into the stigma of NHB males is that most of them have a fatherless upbringing. This is simply 
false, as 2.5 million Black fathers live with their children, while 1.7 million do not, according to the Center for Disease Control and Prevention (Jones \& Mosher, 2013). Actually, Black fathers are more likely than White and Hispanic fathers to spend time playing with their children every day, talk with their children about the day, and help their children with homework (Jones \& Mosher, 2013). Black fathers are least likely than other ethnic groups to report that they never do any of these things (Jones \& Mosher, 2013).

The stereotype that Black fathers are absent in the home is highly damaging to NHB youth because it is associated with very negative outcomes. For example, research shows that child growing up without a father is at least twice as likely to be incarcerated as a child with a mother and father (Harper \& McLanahan, 2004). Dealing with the emotional instability from lower income and stepparents/other relatives can also increase disadvantaging odds, worsening consequences of less supervision and struggles with attachment, which leads to delinquency (Harper \& McLanahan, 2004). To be clear, fatherlessness is still a major issue among Black households, as there are more fathers missing from households in comparison to White and Hispanic ethnic groups (Jones et al., 2013). This could be due to several reasons, such as Black children with more dead or incarcerated fathers, "serial impregnator" fathers, or, much like children of the other ethnic groups, those who have dads who are simply at more distance because they live out of town or out of the country (Levs, 2016). To the contrary though, most men, including Black men, are doing their part (Jones \& Mosher, 2013; Levs, 2016), so NHB males should be reminded of that.

As a message to all pediatricians, adults need to learn to become aware of how public perceptions affect young NHB males along the continuum of education (AAMC, 2015). NHB pediatricians can be especially helpful as role models and contribute to this area in several ways. For example, NHB pediatricians can highlight good statistics and examples of NHB fathers (Jones \& Mosher, 2013) and focus on the importance of the active fatherhood role in homes (Harper \& McLanahan, 2004) for families who come in or that they encounter in the community. This is the reason NHB youth should be encouraged to be involved with children. A daycare job, volunteering in the YMCA, or caring for a newborn cousin can be the spark that motivates NHB men to become excited about a career in the field of maternal and child health, and thus pediatrics. As such, pediatricians play an important role and are in the position to model values like tolerance and inclusion. 


\section{CONCLUSION}

The lack of NHB men in pediatrics is unfortunate because diversity will be key to making a culturally competent medical workforce and decreasing health disparities in the US. In a perfect world, life for NHB males would be easier without the mentioned barriers. Nonetheless, with appropriate approach to the proposed strategies, the authors are optimistic that NHB males have the capacity to be resilient while the medical setting becomes more inclusive towards all. The encouragement of NHB men to aim higher in terms of education and career aspirations, linked with the fearless challenge of discouraging discrimination, will foster a better understanding of our differences and bring us closer to the message of unity for which this country stands.

\section{REFERENCES}

American Academy of Pediatrics (n.d.) Demographics of women physicians and pediatricians. Table details percentage of pediatricians in US by gender and race/ethnicity. Retrieved from https://www.aap.org/enus/Documents/dwmep_women_med_demographics.pdf

Association of American Medical Colleges. (2015). Altering the course: Black males in medicine. Washington, D.C.: Author. Retrieved from https://members.aamc.org/eweb/upload/Altering\%20the\%20Course\%20$\% 20$ Black\%20Males\%20in\%20Medicine\%20AAMC.pdf

Association of American Medical Colleges. (2016). Diversity in the physician workforce: Facts \& figures 2016. Washington, D.C.: Author. Retrieved from http://aamcdiversityfactsandfigures.org/section-ii-current-status-ofus-physician-workforce/

Ben-Zeev, A., Dennehy, T. C., Goodrich, R. I., Kolarik, B. S., \& Geisler, M. W. (2014). When an "educated" black man becomes lighter in the mind's eye: Evidence for a skin tone memory bias. SAGE Open, 4(1). doi: $10.1177 / 2158244013516770$

Committee on Pediatric Workforce. (2013). Enhancing pediatric workforce diversity and providing culturally effective pediatric care: Implications for practice, education, and policy making. Pediatrics, 132(4), E1105E1116. doi:10.1542/peds.2013-2268

Gallegos, A. (2016, September 27). AAMC report shows decline of black males in medicine. AAMC News. Retrieved from https://news.aamc.org/diversity/ article/decline-black-males-medicine/

Harper, C., \& McLanahan, S. (2004). Father absence and youth incarceration. Journal of Research on Adolescence, 14(3), 369-397. doi: 10.1111/j.15327795.2004.00079.x 
Jones, J., \& Mosher, W. (2013). Fathers' involvement with their children: United States, 2006-2010. (National Health Statistics Reports, no. 71). Hyattsville, MD: U.S. Department of Health and Human Services, Centers for Disease Control and Prevention, National Center for Health Statistics.

Khanani, I., Elam, J., Hearn, R., Jones, C., \& Maseru, N. (2010). The impact of prenatal WIC participation on infant mortality and racial disparities. American Journal of Public Health, 100 (Suppl 1), S204-S209.

Levs, J. (2016, July 26). No, most black kids are not fatherless. Huffington Post. Retrieved from https://www.huffingtonpost.com/josh-levs/no-most-blackkids-are-no_b_11109876.html

Morrison, E., \& Cort, D. (2014). An analysis of the medical school pipeline: A high school aspirant to applicant and enrollment view. Analysis in Brief, 14(3). doi:10.13140/RG.2.1.5088.0880.

Noguera, Pedro A. (2003). The trouble with black boys: The role and influence of environmental and cultural factors on the academic performance of African American males. Urban Education, 38(4), 431-459.

Oklahoma Center for Neuroscience. (2010). Mini medical school. Retrieved from https://www.oumedicine.com/docs/ocns-workfiles/mini_med_flyer_2010. pdf?sfvrsn=2

Rao, V., \& Flores, G. (2007). Why aren't there more African-American physicians? A qualitative study and exploratory inquiry of African-American students' perspectives on careers in medicine. Journal of the National Medical Association, 99, 986-993.

Rothman, P. B. (2016, May 27). Diversity in medicine has measurable benefits. Johns Hopkins Medicine: News and Publications. Retrieved from https://www.hopkinsmedicine.org/news/articles/diversity-in-medicine-hasmeasurable-benefits

Saha, S., Guiton, G., Wimmers, P. F., \& Wilkerson, L. (2008). Student body racial and ethnic composition and diversity-related outcomes in U.S. medical schools. Journal of the American Medical Association, 300(10), 11351145. doi:10.1001/jama.300.10.1135

Symposium on Diversity in Health Professions in Honor of Herbert W. Nickens, M.D, \& Smedley, Brian D. (2001). The right thing to do, the smart thing to do: Enhancing diversity in the health professions: Summary of the Symposium on Diversity in Health Professions in honor of Herbert W. Nickens, M.D. National Academy Press.

Thomas, B., Manusov, E. G., Wang, A., \& Livingston, H. (2011). Contributors of black men's success in admission to and graduation from medical school. Academic Medicine, 86(7), 892-900. doi:10.1097/ACM. 0b013e31821d6f3d

Williams, D., \& Sternthal, M. (2010). Understanding racial-ethnic disparities in health: Sociological contributions. Journal of Health and Social Behavior, 51(1 Suppl), S15-S27. doi:10.1177/0022146510383838 
CLARK GILFORD, MSPH, is an alumni student of the University of Miami. Email:cxg786@miami.edu

Manuscript submitted: August 28, 2018 Manuscript revised: September 24, 2018 Accepted for publication: November 30, 2018 